\title{
Reaction of the human granulocyte system in successfully treated bacterial bronchopneumonia
}

\author{
JERZY KRUSZEWSKI, CEZARY SZCZYLIK, * WIESLAW WIKTOR-JEDRZEJCZAK* \\ From the Department of Internal Medicine, Postgraduate Center, Military School of Medicine, Warsaw, \\ and the * Department of Radiation Immunology, Military Institute of Hygiene and Epidemiology, \\ Warsaw, Poland
}

SUMMARY The behaviour of peripheral blood granulocyte pools, nitroblue tetrazolium reduction by granulocytes, migration of granulocytes out of skin windows, serum muramidase activity and bone marrow reserve of granulocytes during uncomplicated bronchopneumonia were studied. The time course of changes in these parameters during infection was established, and suggests maximal changes on day 2 of infection with gradual regression until 30 days after the disease onset, when they disappear.

Granulocytes play an important role in protection against bacterial infection. The significance of the role of the granulocytes is confirmed especially by observations on the incidence and course of bacterial infections in patients with neutropenia. ${ }^{1}$ However, very few data are available on the reaction of the normal human granulocyte system to such conditions..$^{2-8}$ At present, a large number of simple and relatively non-invasive methods is available that make possible evaluation of the indices of the size of various granulocyte pools in man. The simplest test to demonstrate the participation of the granulocyte system during infection is the absolute peripheral blood granulocyte count (AGC). One of the commonest infections associated with granulocytosis is bacterial bronchopneumonia. At present it is not known whether changes in the peripheral blood granulocytes are reflected in the other granulocyte pools, for example, the marginal granulocyte pool (MGP), the bone marrow reserve of granulocytes (BMRG) and the tissue granulocyte pool (TGP); nor is it known what the relation is with granulocyte disintegration.

The aim of the present study was to investigate the kinetics of changes in the granulocyte system during successfully treated uncomplicated bronchopneumonia in previously healthy patients.

\section{Patients and methods}

PATIENTS

The investigations were carried out in 30 previously healthy males aged between 19 and $24 \mathrm{yr}$ treated as Accepted for publication 20 May 1981 inpatients for bronchopneumonia and 15 healthy male volunteers in the same age-range. Before admission to hospital patients were given no antibacterial drugs, but only anti-inflammatory and antipyretic agents. The diagnosis of bronchopneumonia was based on history, physical examination, radiological, and haematological investigations. The nitroblue tetrazolium (NBT) test values were high. Evidence of the bacterial nature of bronchopneumonia was gained by the isolation of likely aetiological agents from the sputum of seven of the patients (Staphyloccus aureus in two patients, Streptococcus pneumoniae in two patients and Pseudomonas aeruginosa, Klebsiella pneumoniae and Acinetobacter alcoaceticus each in one case). There was no other associated disease found and all patients gave a history of symptoms lasting, at the most, four days (mean two days). The antibiotics used in treatment were penicillin, streptomycin, metacycline and gentamicin; expectorants and vitamins were also given. The clinical course of disease was typical; complications were not observed and the duration of treatment was 9-12 days. At the time of the investigations the patients were maintained on a similar diet, participated in no exercises, and did not smoke on the days of investigation. The association of the various tests and investigations with the day of illness is shown in the Table.

\section{METHODS}

Determination of the indices of granulocyte pools The size of circulating granulocyte pool (CGP), 
Table Scheme of the diagnostic procedure carried out during the treatment of pneumonia

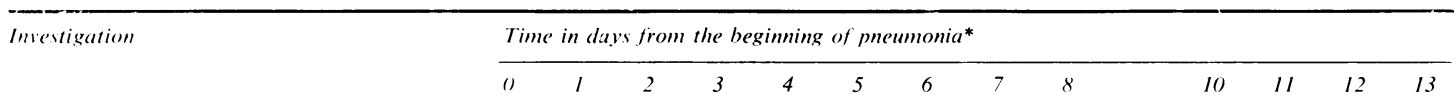

Absolute granulocyte count

NBT-test

Serum muramidase activity

Adrenalin test

Hydrocortisone test

Skin window

Chest $x$-ray

Sputum examination

ESR

Others

*Treatment was usually started on day 2.

marginal granulocyte pool (MGP) and total blood granulocyte pool (TBGP) were measured by testing the responses of AGC to injections of adrenalin and hydrocortisone. Since the time course of the mobilisation of peripheral blood pools by adrenalin is different from the time course of the mobilisation of BMRG by hydrocortisone, it was assumed that these two tests would not interfere with each other and they were performed on the same day.

The investigations were started at 8 am. Patients were fasting and not smoking. The initial count $\left(\mathrm{AGC}_{0}\right)$ was determined in the blood from a fingertip using a haemocytometer. Then patients received $3 \mathrm{mg} / \mathrm{kg}$ of hydrocortisone intravenously and $0.014 \mathrm{mg} / \mathrm{kg}$ of adrenalin subcutaneously into contralateral arm. The subsequent AGC determinations for study of the reaction to adrenalin were carried out after 15 and $30 \mathrm{~min}$. The AGC determinations for study of the reaction to hydrocortisone were made approximately four and five hours later.

The indices of the respective granulocyte pools were calculated from the results of these determinations and were defined as follows:

(i) the size of the CGP was indicated by the initial AGC value $\left(\mathrm{AGC}_{0}\right)$,

(ii) the size of the TBGP was indicated by the maximum value of the $\mathrm{AGC}$ after injection of adrenalin $\left(\mathrm{AGC}_{\mathrm{adr}}\right)$,

(iii) the size of the MGP was indicated by the net increase of AGC after injection of adrenalin,

(iv) the quantitative relation between the size of the CGP and MGP was indicated by the $\%$ increment of the $\mathrm{AGC}_{\mathrm{adr}}$,

(v) the size of the BMRG was indicated by the net increase of AGC after injection of hydrocortisone.

Spontancous NBT reduction test

This test was performed by the method of Park et al. ${ }^{9}$ In accordance with earlier reports ${ }^{9-12}$ the normal state was accepted, when less than $14 \%$ of the granulocytes showed the ability of reducing NBT.
Serum muramidase activity

Serum muramidase activity was measured by the turbidimetric method of Litwack ${ }^{13}$ with hen eggwhite muramidase (Sigma Chemical Co, USA) as a 을 standard. This activity in serum derives mainly from tissue granulocytes ${ }^{14}$ and was used as an index of tissue disintegration of granulocytes.

\section{Skin window}

The quantitative study of the migration of granulocytes from the skin window was used as the index of the size of TGP. Since, in our pneumonia patients, skin was obviously not directly affected by the disease process, this study aimed at measurement of tissue granulocytes in other than infected sites. The test was performed by the method of Rebuck et al. ${ }^{15}$ Briefly, a skin window was made with the use $\overrightarrow{\overrightarrow{0}}$ of a surgical blade and had a surface area of approximately $1 \mathrm{~cm}^{2}$; it was then covered with a coverslip. The glass was changed every two hours during a six-hour period. Subsequently, granulocytes on the three coverslips derived were counted. The number obtained was additionally evaluated according to the scale proposed by Gewurz et al. ${ }^{16}$ The indices of the TGP size were:

(i) the sum of granulocytes on three coverslips, and (ii) the sum of the indices of migration calculated according to the aforementioned scale.

Statistics

The means, standard deviations and $t$-tests were carried out using the $\mathrm{T}-58 \mathrm{C}$ programmed calculator $\mathrm{N}$ (Texas Instruments) and manufacturer's statistical module.

\section{Results}

PERIPHERAL BLOOD GRANULOCYTE POOLS IN BACTERIAL PNEUMONIA A highly significant $(\mathrm{p}<0.001)$ increase of the $\stackrel{\bigcirc}{\Phi}$ $\mathrm{AGC}_{0}$ and $\mathrm{AGC}_{\mathrm{adr}}$ was observed in acute phase of $\stackrel{\mathbb{Q}}{\mathscr{Q}}$ bacterial pneumonia in comparison with the group of 

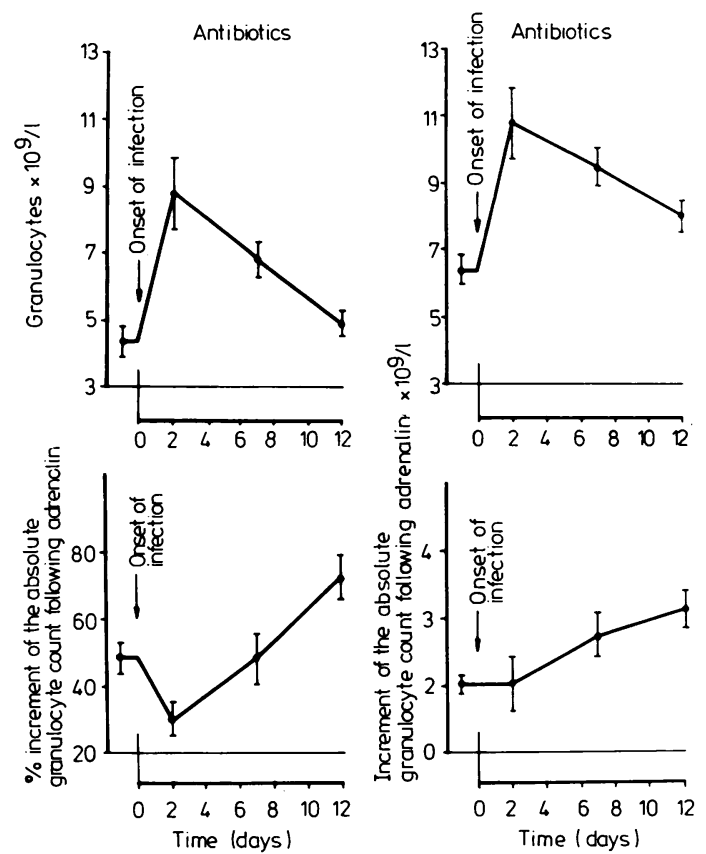

Fig. 1 Changes of the indices of the peripheral blood granulocyte pools in the course of bronchopneumonia treated with antibiotics. Upper left-initial granulocyte count-index of circulating granulocyte pool; upper right-maximum granulocyte count following adrenalinindex of total blood granulocyte pool; lower left$\%$ increment granulocyte count following adrenalinindex of the relation of size of marginal granulocyte pool to size of circulating granulocyte pool; lower rightnet increment of the absolute granulocyte count following adrenalin-index of marginal granulocyte pool.

healthy subjects (Fig. 1). During effective antibacterial treatment a gradual $(p<0.01)$ decrease in the values of these parameters occurred with a return to the normal values 15 days after the onset of the disease. A slightly different pattern was observed for the parameters of the MGP. Although in acute phase of bacterial pneumonia the net AGC increase after adrenalin was similar to that in healthy subjects, the \% increment was significantly $(p<0.01)$ decreased. During the treatment the values of both these parameters increased gradually $(p<0.05)$ and in about four weeks after the onset of the disease they resembled the values in healthy subjects.

FUNCTIONAL STATUS OF PERIPHERAL BLOOD GRANULOCYTES IN BACTERIAL PNEUMONIA The functional status of peripheral blood granulocytes was studied by means of the spontaneous NBT reduction test. In relation to the group of
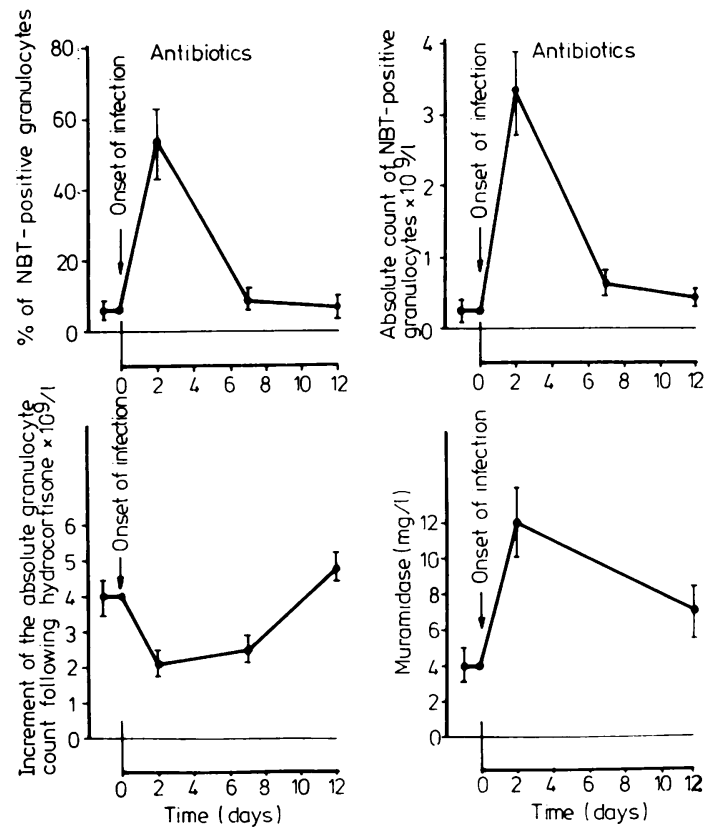

Fig. 2 Changes in various indices of the granulocyte system in the course of bronchopneumonia treated with antibiotics. Upper left-frequency of NBT-positive granulocytes in peripheral blood; upper right-absolute count of NBT-positive granulocytes in peripheral blood; lower left-net increment of the absolute granulocyte count following hydrocortisone-index of the bone marrow reserve of granulocytes; lower right-serum muramidase activity-index of the tissue disintegration of granulocytes.

healthy subjects, in the acute stage of bacterial pneumonia a highly significant $(\mathrm{p}<0.001)$ rise in the values of both the frequency as well as of the absolute count of NBT-reducing cells in peripheral blood was observed (Fig. 2). With continued effective treatment these parameters fell steeply so that from the 5th day of treatment they were similar to those in healthy subjects.

\section{BMRG IN BACTERIAL PNEUMONIA}

In relation to the group of healthy subjects a significantly $(\mathrm{p}<0.01)$ decreased response to hydrocortisone was observed in the acute stage of the disease. During the treatment this value increased gradually ( $<<0.01$ ), and about four weeks after the onset of the disease it reached the values observed in healthy subjects.

GRANULOCYTE DISINTEGRATION IN TISSUES AND TGP SIZE IN BACTERIAL PNEUMONIA In relation to the group of healthy subjects a 
Kruszewski, Szczylik, Wiktor-Jedrzejczak

significant $(p<0.001)$ increase of the activity of serum muramidase was observed in the acute stage of the disease (Fig. 2). Additionally the number of granulocytes migrating out of skin window and the migration index were increased $(p<0.05)$ in this phase of the disease (Fig. 3). During the treatment a gradual decrease in the values of these parameters was observed with return to their normal levels in four weeks after the onset of the disease. The pattern of reaction of the granulocyte system, during effectively treated bacterial pneumonia, is shown in Fig. 4.

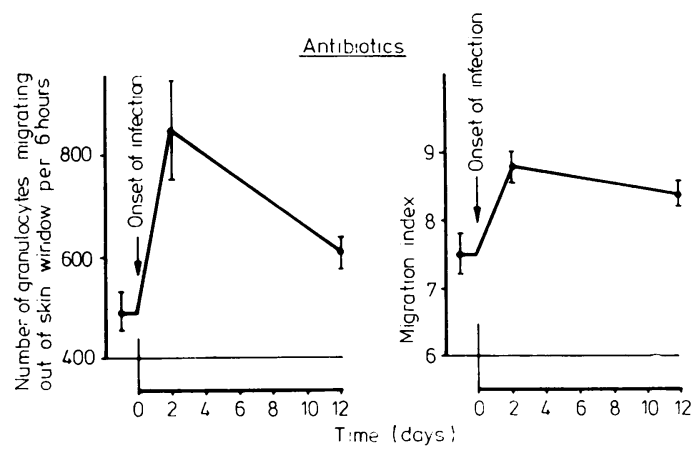

Fig. 3 Changes in skin window reaction in the course of bronchopneumonia treated with antibiotics. Lefttotal number of granulocytes out of the $1 \mathrm{~cm}^{2}$ skin window over six hours; right-migration index calculated according to Gewurz et al. ${ }^{16}$

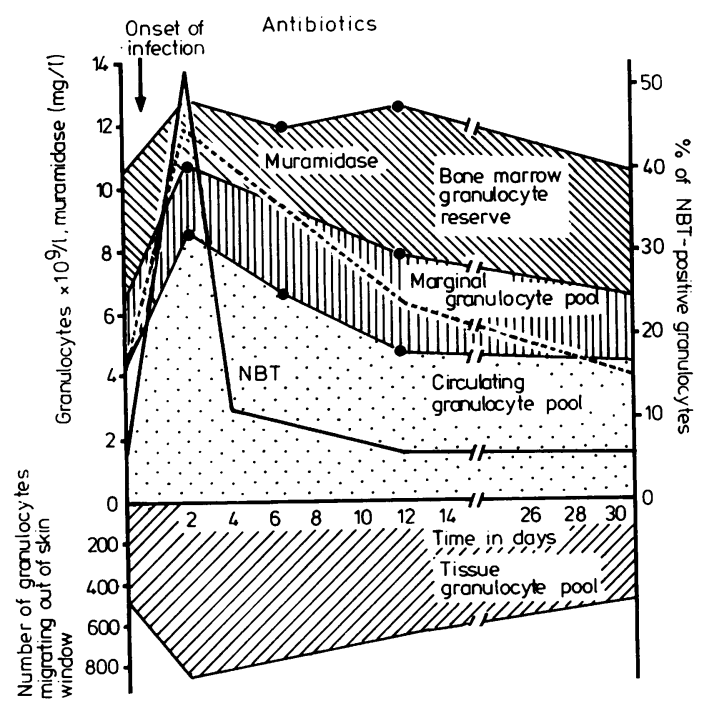

Fig. 4 Scheme of the reaction of granulocyte system to successfully treated bacterial bronchopneumonia

\section{Discussion}

The direct cause of the observed reaction of the $\overrightarrow{\vec{F}}$ granulocyte system was presumably the increaseddisintegration of granulocytes in the pulmonary등 tissue subsequent to their interaction with bacteria $\overline{\bar{c}}$ and bacterial toxins. An expression of this process $\widehat{\mathbb{D}}$ was the increase of serum muramidase activity, since it is known that this increase depends mainly ${ }^{\infty}$ on the release of this enzyme from disintegrating. $\vec{\circ}$ granulocytes in the tissues. ${ }^{14} \mathrm{~A}$ consequence of $\overrightarrow{\vec{\omega}}$ increased granulocyte disintegration in the acute ${ }_{\sigma}^{\omega}$ stage of bacterial pneumonia was a local deficiency of granulocytes in the infected tissues. Presumably this, through a feedback mechanism, stimulated the transition of granulocytes into tissues. In agreement $\vec{y}$ with this, it was demonstrated in the skin window $y$

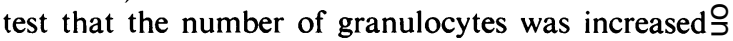
also in the tissues not directly affected by bacterialinfection. Most probably, the changes in the TBGP were subsequent to the above described changes in? the tissue pool. It was found that in the acute stage of bacterial pneumonia the TBGP and CGP were $\vec{\bullet}$ increased. This is commonly observed in clinicalo practice and it may be produced through the well ${ }^{N}$ known release of granulocytes from their marrowo reserves into the circulating blood from the effect of the action of bacteria and their toxins. ${ }^{17}$ It is $\overline{0}$ possible that a regulatory feedback mechanism, activated by tissue deficiency of granulocytes, may $\varnothing$ effect this release. In this phase no absolute change $\overrightarrow{\vec{O}}$ was observed in the parameters of the MGP, but it 3 was diminished with relation to the CGP. In the latter phase of infection, when as a result of anti-o bacterial treatment inflammatory reaction began to decrease, the consequences of stimulation of marrow: pools of the granulocytes system began to prevail. 3 Therefore, absence of stimulated granulocytes in peripheral blood, normalisation of serum murami-을 dase activity, and of the skin window reaction were associated with the increase of all peripheral blood granulocyte pools and BMRG. As a consequence of the disappearance of the cause of this stimulation - that is, infection, these signs gradually disappeared and subsequently the granulocyte system returned to $\mathrm{N}$ its preinfection state.

These studies have drawn a common line for $\omega$ several earlier studies on the behaviour of the granulocyte system during bacterial infection. In none of these studies were so many parameters of the system measured simultaneously. The increase in ${ }^{+}$ muramidase activity in the acute stage of bacterial ${ }_{0}^{0}$ infection in both man and experimental animals has been observed by several authors. ${ }^{18}$ This activity may $\frac{\stackrel{\odot}{\Phi}}{8}$ also be increased in acute leukaemias of granulocyteo or monocyte lineages and during renal failure.14 190 
None of these conditions was present in our patients. The effect of experimental infection, in dogs, on peripheral blood granulocyte pools was studied by Marsh et al using DFP ${ }^{32}$ labelled granulocytes. ${ }^{8}$ The most significant changes were observed in MGP, which was increased in the acute phase of infection. More pronounced increases of this pool were observed in animals with high fever. Changes very similar to those described in this study, were observed by Jedrzejczak et al who studied granulocytosis of infection. ${ }^{20}$ As based on this study and on data of Joyce et $a l,{ }^{21}$ the relative increase of CGP in infection is simply due to the granulocytosis and not to a more specific phenomenon. In the latter two studies it was shown that the capacity of the vascular system to marginate neutrophils is limited and increases in the absolute granulocyte count result in the proportion of cells in the marginal pool decreasing.

There is such a multiplicity of data on increased frequency of NBT-positive neutrophils in peripheral blood during infection that it is not necessary to reaffirm this observation here. However, in agreement with our ${ }^{12}$ and other earlier studies, ${ }^{22}$ the disappearance of NBT-positive cells was the first clinical sign of the control of the infection by antibiotic treatment and simultaneously it was the beginning of recovery process.

A similar decrease of BMRG in bacterial infection was observed by Szmigielski, (personal communication, 1978). This author studied the effect of experimental infection (Staphylococcus aureus) of rabbits and recorded that peripheral signs of stimulation of the granulocyte system are secondary to indirect and direct stimulation of bone marrow. Therefore, in the bone marrow the total number of cells of granulocyte system was increased with the most significant increase of cells of the proliferating pool as simultaneously evidenced by increased ${ }^{3} \mathrm{H}$-thymidine incorporation (autoradiography).

Further studies are in progress aimed at determining the pattern of bone marrow reaction in man to bacterial bronchopneumonia.

\section{References}

${ }^{1}$ Finch SC. Granulocytopenia. In: Williams WJ, Beutler E, Erslev AJ, Wayne Rundles R, eds. Hematology. New York: MacGraw Hill Co, 1972:628-54.

2 Wintrobe MM, Lee GR, Boggs DR, Bithell TC, Athens JW, Foerster J, eds. Clinical hematology. Philadelphia: Lea \& Febiger, 1974:1266-312.

${ }^{3}$ Antonioli IA, Vannotti A. Metabolisme du granulocyte dans l'inflammation. Schweiz Med Wschr 1967;97: 113-23.

${ }^{4}$ Martinez-Maldonado M, Menendez-Corrada R, Rivera de Sala A. Diagnostic value of alkaline phosphatase in leucocytes. Am J Med Sci 1964;248:175-83.

${ }^{5}$ Szmigielski S. 5'-nucleotidase activity in human blood granulocytes during acute infections. Folia Haematol (Leipz) 1965;84:402-5.

- Athens JW, Haab OP, Raab SO, et al. Leukokinetic studies. XI. Blood granulocyte kinetics in polycythemia vera, infection and myelofibrosis. J Clin Invest 1965;44:77888.

' Galbraith PR, Valberg LS, Brown M. Patterns of granulocyte kinetics in health, infection and carcinoma. Blood 1965; 25 :683-92.

${ }^{8}$ Marsh JC, Boggs DR, Cartwright GE, Wintrobe MM. Neutrophil kinetics in acute infection. J Clin Invest 1967;46:1943-53.

${ }^{9}$ Park BH, Fikrig SM, Smithwick EM. Infection and nitroblue tetrazolium reduction by neutrophils. Lancet $1968 ; \mathrm{ii}: 532-4$

10 Jedrzejczak WW, Siekierzyński M. Nitroblue tetrazolium (NBT) test: criteria for false positivity and its use in practice. Folia Haematol (Leipz) 1976;103:63-7.

${ }^{11}$ Jedrzejczak WW, Siekierzyński M, Sułek K. Evaluation of the usefulness of nitroblue tetrazolium reduction test for detection of bacterial infection in cancer patients. Neoplasma 1975;22:323-8.

${ }^{12}$ Kruszewski J, Markiewicz K, Jedrzejczak WW. The spontaneous reduction of nitroblue tetrazolium as a test of sensitivity to antibiotics in patients with bacterial pneumonia. Revue Roumaine de Medicine: Med Interne 1979;17:279-83.

${ }^{13}$ Litwack G. Photometric determination of lysozyme activity. Proc Soc Exp Biol Med 1955;89:401-3.

14 Hansen NE. Plasma lysozyme-a measure of neutrophil turnover: an analytical review. Ser Haematol 1974;7: $1-87$.

${ }^{15}$ Rebuck JW, Crowley JH. A method of studying leukocytic functions in vivo. Ann NY Acad Sci 1953;59: 757-805.

${ }^{16}$ Gewurz JW, Page AR, Pickering RJ, Good RA. Complement activity and inflammatory neutrophil exudation in man. Int Arch Allergy Appl Immunol 1967;32:64-90.

${ }^{17}$ Craddock CG, Perry S, Ventzke LE, Lawrence JS. Evaluation of marrow granulocytic reserves in normal and disease states. Blood 1960;15:840-55.

${ }^{18}$ Crowder JG, White AC. Selective changes in white cell lysosomal enzymes in man. Am J Med Sci 1968;255: 327-35.

${ }^{19}$ Osserman EV, Lawrol PP. Serum and urinary lysozyme (muramidase) in monocytic and monomyelocytic leukemia. J Exp Med 1966;124:921-51.

20 Jedrzejczak WW, Sułek K, Siekierzyński M. Mobilization of the marginal pool of neutrophils with epinephrine. Results in healthy persons, patients with neutropenias, patients with neutrophilias, and patients with changes in neutrophil count induced by cancer chemotherapy. Haematologica (Pavia) 1979;64:586-96.

21 Joyce RA, Boggs DR, Hasiba U, Srodes CH. Marginal neutrophil pool size in normal subjects and neutropenic patients as measured by epinephrine infusion. $J$ Lab Clin Med 1976;88:614-20.

${ }^{22}$ Freeman R, King B, Kite P. Serial nitroblue tetrazolium tests in the management of infection. J Clin Pathol 1973; 26:57-9.

Requests for reprints to: Wieslaw Wiktor-Jedrzejczak, Department of Radiation Immunology, Military Institute of Hygiene and Epidemiology, 00-909 Warsaw, Szaserów 128, Poland. 